\title{
Microwave-assisted green synthesis of silver nanoparticles from Fraxinus excelsior leaf extract and its antioxidant assay
}

\author{
Mehtab Parveen $^{1} \cdot$ Faheem Ahmad $^{1} \cdot$ Ali Mohammed Malla ${ }^{1} \cdot$ Shaista Azaz $^{1}$
}

Received: 3 February 2015/Accepted: 10 March 2015/Published online: 22 March 2015

(C) The Author(s) 2015. This article is published with open access at Springerlink.com

\begin{abstract}
The biosynthesis of nanoparticles has been proposed as a cost effective and environmentally benevolent alternative to chemical and physical methods. In the present study, microwave assisted synthesis of silver nanoparticles (AgNPs) has been demonstrated using leaf extract of Fraxinus excelsior reducing aqueous $\mathrm{AgNO}_{3}$ solution. The synthesized nanoparticles have been characterized on the basis of fourier transform infrared spectroscopy (FT-IR), UV-Vis spectroscopy, scanning electron microscopy (SEM), transmission electron microscopy (TEM) and energy dispersive X-ray (EDX) analysis. The presence of a characteristic surface plasmon resonance (SPR) absorption band at $425 \mathrm{~nm}$ in UV-Vis reveals the reduction of silver metal ions into silver nanoparticles. FTIR analysis was carried out to probe the possible functional group involved in the synthesis of AgNPs. Further leaf extracts and AgNPs were evaluated for antiradical scavenging activity by 1,1-diphenyl-2-picryl-hydrazyl (DPPH) assay.
\end{abstract}

Keywords Microwave $\cdot$ Biosynthesis $\cdot$ Fraxinus excelsior $\cdot$ Silver nanoparticles $\cdot$ Antioxidant activity

\section{Introduction}

Exploitation of biological materials in synthesis of nanoparticles is one of the hottest thrust areas in the modern nanoscience. The application of nanoscale

Mehtab Parveen

mehtab.organic2009@gmail.com

1 Division of Natural Products, Department of Chemistry, Aligarh Muslim University, Aligarh 202002, India materials and structures, usually ranging from 1 to $100 \mathrm{~nm}$, has become an emerging area in the field of nanoscience and nanotechnology since from the past few decades (Wang and Wang 2014). Nanoparticles exhibit completely new or improved properties based on specific characteristics such as size, distribution and morphology. The potential benefits of nanoparticles in biomedical and industrial applications for human health and environment are now well documented (Lanone and Boczkowski 2006). Among the various nanoparticles, metal nanoparticles assume special importance because they are easier and cheaper to synthesize and possess promising applications (Juan et al. 2012). Additionally, metal nanoparticles display a surface plasmon resonance (SPR) absorption in the UV-Vis region which arises from the coherent existence of free electrons in the conduction band due to the small particle size (Burda et al. 2005; Tessier et al. 2000). The band shift is dependent on the particle size, chemical surrounding, adsorbed species on the surface and dielectric constant (Mulvaney 1996). A unique characteristic of these synthesized metal particles is that a change in the absorbance or wavelength gives a measure of the particle size, shape and interparticle properties (Mulvaney 1996; Knoll and Keilmann 1999). To date, noble metals like Ag, $\mathrm{Au}, \mathrm{Pd}, \mathrm{Pt}$ have been widely used for the synthesis of metallic nanoparticles (Doria et al. 2012). Among these, silver nanoparticles (AgNPs) have become the focus of much research interest due to their unique optical, electrical and biological properties which offers a number of exciting potential applications in various fields including catalysis, electronics and biology (Prabhu and Poulose 2012). They possess an excellent biocompatibility and low toxicity (Pauksch et al. 2014). Silver nanoparticles have been documented in the field of biomedical (Chaloupka et al. 2010), drug delivery (Prow et al. 2011), food 
industries (Chaudhry and Castle 2011), agriculture (Nair et al. 2010), textile industries (Kelly and Johnston 2011), water treatment (Dankovich and Gray 2011), antioxidant (Niraimathi et al. 2013), antimicrobial (Sankar et al. 2013), anti-cancer (Boca et al. 2011), cosmetics (Jain et al. 2009), ointments (Murphy 2008) and larvicides (Roopan et al. 2013).

A number of methods have been documented in the literature for the synthesis of silver nanoparticles, such as thermal decomposition (Navaladian et al. 2007), electrochemical (Starowicz et al. 2006), microwave assisted process (Sreeram et al. 2008) and green chemistry (Begum et al. 2009). However, most of the chemical and physical methods employed for the synthesis and production of nanoparticles involve the use of hazardous and toxic chemicals, low material conversions and high energy requirements. In view of the numerous biological applications of the nanoparticles, the development of simple, biocompatible, non-toxic and eco-friendly protocol for the synthesis of nanoparticles is of considerable interest. Green synthesis using biological organisms such as microorganisms (Otari et al. 2012) and plant extracts (Kumar et al. 2011) provides advancement over chemical and physical method as it is environmentally benevolent, simple, inexpensive, easily scaled up for large-scale synthesis and further there is no need to use high pressure, energy, temperature and toxic chemicals (Ramya and Subapriya 2012). Plant extracts may provide a better alternative to synthesize silver nanoparticles since most microorganisms that have been reported for the synthesis of silver nanoparticles are pathogenic to either plants and/or humans (Silver 2003; Ahmed et al. 2003). The plant extracts are believed to be more beneficial over other biological process as it eliminates the elaborative process of cell culturing, simple, efficient and low cost generally leads to the formation of crystalline nanoparticles with a variety of shapes and sizes.

Microwave heating holds many advantages over traditional heating as its operation provides increased reaction kinetics, rapid initial heating eventually leading to enhanced reaction rates culminating in clean reaction products with higher yields (Nadagouda et al. 2011). Microwave heating holds great importance in the regime of nanoparticle synthesis as its controlled high temperature enhances the nucleation process by which nanoparticles are initially created (Jiang et al. 2006). It has already been reported that microwave heating as compared to traditional heating, creates nanoparticles of higher degrees of crystallinity and provides greater control over the shape and morphology of the nanostructures produced (Tsuji et al. 2005). A number of studies have been documented that illustrate facile production of nanoparticles using microwave heating (Nadagouda et al. 2011; Jiang et al. 2006;
Tsuji et al. 2005) and it has now become an attractive alternative pathway in the synthesis of nanoparticle.

Fraxinus excelsior L. (Family: Oleaceae), commonly known as 'ash' or 'European ash', is an anemophilous tree native to the countries of temperate Asia and Europe (Hemmer et al. 2000; Eddouks et al. 2002). Phytochemists have reported the isolation of various compounds from Fraxinus excelsior which includes fraxin, fraxetin, scopoletin, esculin and excelsioside, a secoiridoid glucosides (Renwart et al. 1992; Damtoft et al. 1992). The parts of the plants have been reported to be effective in the treatment of various diseases. The barks of Fraxinus excelsior have long been used as antibacterial (Middleton et al. 2005), seed extract has been used as a potent hypoglycemic agent (Visen et al. 2009). The alcoholic extract of bark has been reported to possess an anti-inflammatory property (Ghazaly et al. 1992). In addition to this, Fraxinus excelsior has been proved to be beneficial in the treatment of hypertensive and obese disorders (Monto et al. 2014).

In the present study, we report a simple, low cost, environmentally benign and microwave assisted green method for the synthesis of silver nanoparticles using the aqueous leaf extract of Fraxinus excelsior. To the best of our knowledge, no reports pertaining to the microwave method for the synthesis of AgNPs using aqueous extract of Fraxinus excelsior leaves are yet available. Synthesized silver nanoparticles have been characterized on the basis of UV-Vis, FT-IR, SEM-EDX and TEM analysis. The synthesized AgNPs were also tested for antiradical screening activity.

\section{Materials and methods}

\section{Materials}

Fraxinus excelsior leaves were used to make the aqueous extract. Silver nitrate $\left(\mathrm{AgNO}_{3}\right), 1,1$-diphenyl-2-picryl-hydrazyl (DPPH) and ascorbic acid of analytical grade were purchased from Sigma-Aldrich (India) and used without further purification. Triply distilled de-ionized water was used throughout the experiments. Microwave synthesis reactor (Anton Paar-Monowave 300) was used to synthesize silver nanoparticles.

\section{Preparation of the leaf extracts}

Fresh Fraxinus excelsior leaves were collected from the Kashmir (India) and used to retrieve their extraction. Freshly prepared aqueous and ethanolic leaf extract was used within two weeks for all synthesis. The leaves were first rinsed thoroughly with tap water, followed by distilled water to remove the dust particles, air-dried and incised 
into small pieces. $25 \mathrm{~g}$ of finely cut leaves were weighed and transferred into 250-mL Erlenmeyer flask containing $100 \mathrm{~mL}$ distilled water and boiled for $30 \mathrm{~min}$. The raw extract obtained was filtered in hot condition using Whatman No. 1 filter paper to remove fibrous impurities. The aqueous extracts were then refrigerated and further used for the biosynthesis of silver nanoparticles from silver nitrate. Similarly, the ethanolic extracts were prepared by refluxing $25 \mathrm{~g}$ of finely cut leaves in ethanol.

\section{Synthesis of silver nanoparticles}

Silver nanoparticles were synthesized using microwave synthesis reactor (Anton Paar-Monowave 300). In a typical reaction procedure, $1 \mathrm{~mL}$ of aqueous extract solution was added to $20 \mathrm{~mL}$ of $1 \times 10^{-3} \mathrm{M}$ aqueous silver nitrate solution under stirring. The solution mixture was then exposed to microwave irradiation at a temperature of $90{ }^{\circ} \mathrm{C}$ with a fixed frequency of $2.45 \mathrm{GHz}$. After microwave irradiation treatment, the resultant colloidal solutions were naturally cooled to room temperature. The change in color of a mixture of $\mathrm{AgNO}_{3}$ and leaf extract from yellow to brown indicates the biosynthesis of silver nanoparticles. The strong SPR band at $425 \mathrm{~nm}$ in UV-Vis spectra thus confirms the formation of silver nanoparticles. The AgNPs obtained by leaf extract were centrifuged at $5000 \mathrm{rpm}$ for $5 \mathrm{~min}$ and subsequently dispersed in sterile distilled water to get rid of any uncoordinated biological materials. The dried powders were then used for further characterization. The concentration variation of aqueous leaf extract from 1 to $3 \mathrm{~mL}$ and silver nitrate solution from 1 to $5 \times 10^{-3} \mathrm{M}$ were adjusted to investigate their effect on the formation of silver nanoparticles.

\section{Characterization techniques}

The bio reduction of pure silver ions was monitored by measuring the UV-Vis spectrum of the solution. UV-Vis absorption spectra were recorded using PerkinElmer UV Win Lab spectrophotometer. The size and morphology of nanoparticles were investigated by TEM Hitachi (H-7500) and SEM JEOL (JSM6100). Fourier transform-infrared spectra for Fraxinus excelsior leaf extract and silver nanoparticles were obtained in the range of $4000-400 \mathrm{~cm}^{-1}$ with an FT-IR (PerkinElmer Spectrum 2000 FTIR) by $\mathrm{KBr}$ pellet method. In addition, the presence of $\mathrm{Ag}$ in the sample was confirmed by EDX spectroscopic analysis.

\section{Antioxidant assay}

The biosynthesized silver nanoparticle, the aqueous and the ethanolic leaf extract were tested for their antioxidant property by 1,1-diphenylpicrylhydrazyl (DPPH) method
(Kato et al. 1988). In this procedure, drug stock solution $(1 \mathrm{mg} / \mathrm{mL})$ was diluted to final concentration of $2,4,6,8$, 10 and $12 \mu \mathrm{g} / \mathrm{mL}$ in methanol. Methanolic DPPH solution ( $1 \mathrm{~mL}, 0.3 \mathrm{mmol}$ ) was added to $3.0 \mathrm{~mL}$ of drug solution of different concentrations. The tube was kept at an ambient temperature for $30 \mathrm{~min}$ and the absorbance was measured at $517 \mathrm{~nm}$ in UV VIS-1800 spectrophotometer. The scavenging activity was calculated by following formula:

$\%$ scavenging activity $(\mathrm{SA})=\left[\left(A_{\text {control }}-A_{\text {sample }}\right) / A_{\text {control }}\right] \times 100$

Where $A_{\text {control }}$ is the absorbance of the L-ascorbic acid (standard) and $A_{\text {sample }}$ is the absorbance of different samples. The methanolic DPPH solution $(1 \mathrm{~mL}, 0.3 \mathrm{mM})$ was used as control. The inhibitory concentration $\left(\mathrm{IC}_{50}\right)$ value represents the concentration required to exhibit $50 \%$ antiradical activity. The $\mathrm{IC}_{50}$ values were calculated by the linear regression analysis of dose-response curve plotted between $\%$ inhibition and concentration. The experiments were run in triplicates.

\section{Results and discussion}

\section{UV-Vis spectral analysis}

It is a well-known fact that silver nanoparticles exhibit brownish color in aqueous solution due to the excitation of surface plasmon vibrations in silver nanoparticles (Krishnaraj et al. 2010). It was observed that microwave irradiation of a mixture of aqueous Fraxinus leaf extract and silver nitrate $\left(\mathrm{AgNO}_{3}\right)$ results in the gradual change in color from light yellowish to brown indicating the synthesis of silver nanoparticles (Fig. 1). The formation of silver nanoparticles was further confirmed by using UVVis spectroscopic technique which has been frequently used to characterize the synthesized metallic nanoparticles. In order to study the effect of exposure time of microwave irradiation on the synthesis of AgNP, periodically aliquots of the reaction solution were taken and subjected to UVVis spectroscopy measurements. The absorbance intensity of the reaction mixture increases exponentially with time as shown in Fig. 1. It can be inferred from the Fig. 1 that the metal ion reduction occurred very rapidly and about $94 \%$ of the reduction of $\mathrm{Ag}^{+}$ions was completed in $90 \mathrm{~s}$. It was observed that there was a drastic reduction in reaction kinetics from irradiation time of $90-150 \mathrm{~s}$, as reaction rate changes to linear phase. The further irradiation beyond $150 \mathrm{~s}$ does not enhance the reaction rate confirming the completion of reaction. The reaction medium behavior fluctuates with time kinetics and the color intensity of reaction mixture also increases evenly with time of microwave exposure as shown in inset of Fig. 1. 
Fig. 1 Intensity graph of reaction mixture containing aqueous $10^{-3} \mathrm{M} \mathrm{AgNO}_{3}$ solution and leaf extract versus time indicating that the $90 \%$ of AgNP biosynthesis completed in $90 \mathrm{~s}$. Inset increase in the color intensity of the reaction mixture with time

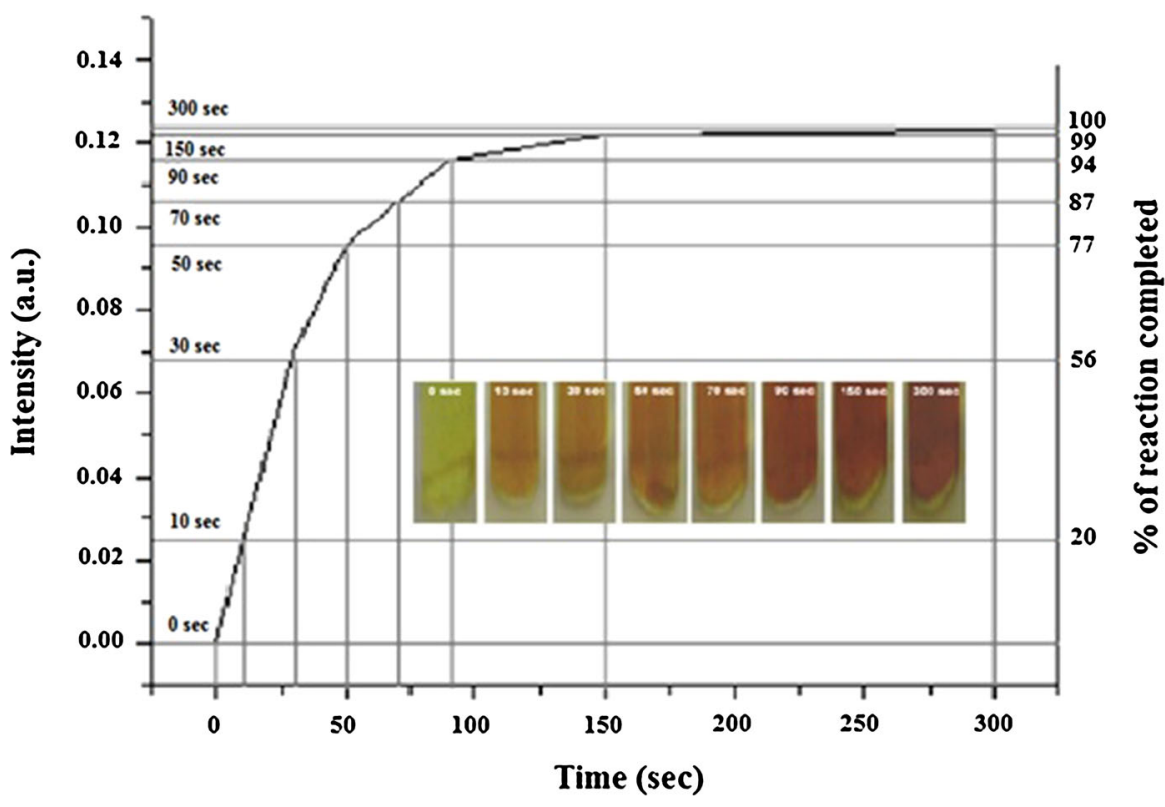

The effect of variation in concentration on the synthesis of silver nanoparticles was also examined by adjusting the concentration of leaf extract and silver nitrate solution. UV-Vis spectroscopy of synthesized silver nanoparticles using $10^{-3}$ $\mathrm{M} \mathrm{AgNO}_{3}$ with different volume fractions of extract are shown in Fig. 2a. It exhibited the characteristic SPR absorption band at $425 \mathrm{~nm}$ for yellowish brown silver nanoparticles when $2 \mathrm{~mL}$ extract solution was used. It has been observed that the intensity of SPR band was found to be less with the $1 \mathrm{~mL}$ extract solution. Moreover at higher extract concentration $(3 \mathrm{~mL})$, the solution becomes hazy probably due to the presence of excess biomaterials and again the intensity of absorption band decreases. It was concluded that $2 \mathrm{~mL}$ extract solution is the optimum concentration for the present green synthesis of Ag nanoparticles. A concentration variation study of $\mathrm{AgNO}_{3}$ using $2 \mathrm{~mL}$ aqueous extract was carried out with concentration of $\mathrm{AgNO}_{3}\left(1 \times 10^{-3}\right.$ to $\left.5 \times 10^{-3} \mathrm{M}\right)$. As can be seen from the Fig. 2b, with the increase in concentration of $\mathrm{AgNO}_{3}$ there is steady increase in intensity of $425 \mathrm{~nm}$ SPR band. Increasing intensity of the $425 \mathrm{~nm}$ SPR band indicates the increasing concentration of the nanoparticles.

\section{FT-IR analysis}

Fourier transform-infrared analysis was performed to spot the possible biomolecules responsible for the reduction of the $\mathrm{Ag}^{+}$ions and capping of the reduced AgNPs synthesized using Fraxinus excelsior leaf extract. It is evident from FT-IR spectra that there is no significant change in absorption bands of the Fraxinus excelsior leaf extract and synthesized AgNPs (Fig. 3). The FT-IR spectrum of aqueous leaf extract Fig. 3a showed strong absorption (a)
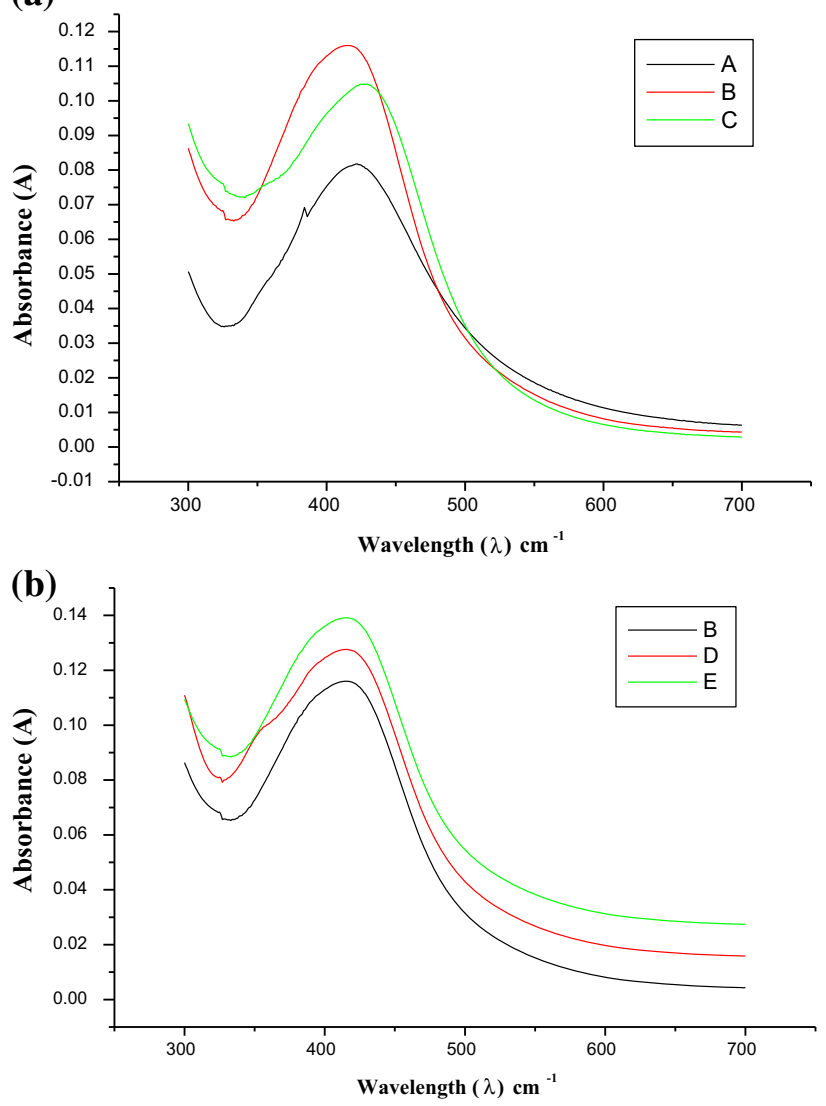

Fig. 2 a UV-Vis absorption spectra of AgNPs synthesized by treating $10^{-3} \mathrm{M}$ aqueous $\mathrm{AgNO}_{3}$ solution with different leaf extract concentrations ( $A 1 \mathrm{~mL}, B 2 \mathrm{~mL}$ and $C 3 \mathrm{~mL}$ ), b UV-Vis absorption spectra of AgNPs synthesized by treating $2 \mathrm{~mL}$ leaf extract solution with different concentration of $\mathrm{AgNO}_{3}$ solutions $\mathrm{B}\left(10^{-3} \mathrm{M}\right), \mathrm{D}$ $\left(3 \times 10^{-3} \mathrm{M}\right)$ and $\mathrm{E}\left(5 \times 10^{-3} \mathrm{M}\right)$ 
Fig. 3 FT-IR spectrum of a aqueous leaf extract, b synthesized AgNPs (a)
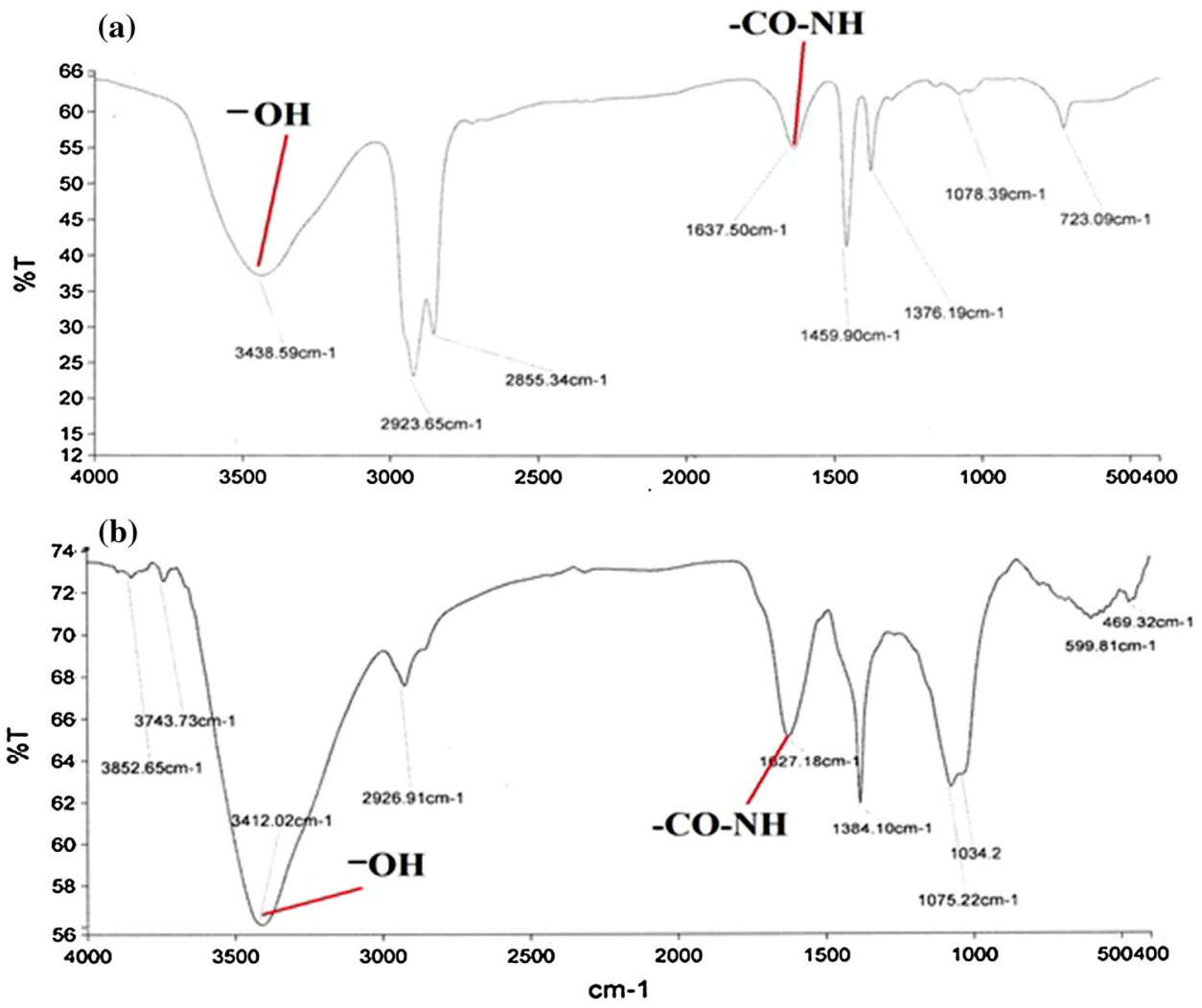

bands at $3438,2923,1637,1376$ and $1078 \mathrm{~cm}^{-1}$. The intense broad absorption bands at $3438 \mathrm{~cm}^{-1}$ is the characteristic of the hydroxyl functional group in alcohols and phenolic compounds. A band at $2923 \mathrm{~cm}^{-1}$ corresponds to the aliphatic $-\mathrm{CH}$ stretching. Similarly a band at $1637 \mathrm{~cm}^{-1}$ has been assigned to the amide I band of the proteins released by the Fraxinus leaves. It has been reported by (Lin et al. 2005) that the hydroxyl group of alcohols and carbonyl groups from the amino acid residues and peptides of proteins have a strong affinity to bind metals, so that they can act as encapsulating agent and thus protect the nanoparticles from agglomeration. A band at $1376 \mathrm{~cm}^{-1}$ corresponds to the geminal methyl and a weak band at $1078 \mathrm{~cm}^{-1}$ has been assigned to ether $(\mathrm{C}-\mathrm{O}-\mathrm{C})$ linkage. The FT-IR spectrum of the synthesized silver nanoparticle Fig. 3b showed bands at 3412, 2926, 1627, 1384 , and $1075 \mathrm{~cm}^{-1}$. A band at $3412 \mathrm{~cm}^{-1}$ corresponds to hydroxyl group in alcohols and phenols, similarly a band at $1627 \mathrm{~cm}^{-1}$ is assigned to the stretching vibration of CO$(\mathrm{NH})$ group. A small but prominent decrease in intensity of a band from 3438 to $3412 \mathrm{~cm}^{-1}$ by a value of $\left(26 \mathrm{~cm}^{-1}\right)$ is believed to be due to reduction of $\mathrm{AgNO}_{3}$. This shift in absorption frequency signifies the involvement of $-\mathrm{OH}$ group in reduction process. On the other hand, the shift of a band from 1637 to $1627 \mathrm{~cm}^{-1}$ is attributed to the possible involvement of $\mathrm{CO}-(\mathrm{NH})$ group also in the reduction of silver nanoparticles. Moreover, bands at 2926, 1384 and
$1015 \mathrm{~cm}^{-1}$ correspond to aliphatic $-\mathrm{CH}$ stretching, geminal methyl and ether linkage respectively. This data indicates that the synthesized AgNPs using the Fraxinus excelsior leaf extracts is encompassed by organic materials like proteins and metabolites such as terpenoids having functional groups of amines, alcohols, ketones, aldehydes and carboxylic acids.

\section{Probable mechanism for the reduction of $\mathrm{Ag}^{+}$ions}

The reduction of silver ions by the leaf extract of Fraxinus excelsior is believed to be due to the presence of natural biomolecules such as flavonoids, alkaloids, glycosides, terpenoids, phenolic compounds, amino acid residues and peptides of protein. It is a well-established fact that phenolic compounds play a major role in the reduction of silver $\left(\mathrm{Ag}^{+}\right)$ions (Arunachalam et al. 2013). A possible mechanism proposed for the reduction of $\mathrm{Ag}^{+}$is presented in Scheme 1. Phytochemical analysis of Fraxinus excelsior has shown the presence of a phenolic coumarin fraxin, reported by (Renwart et al. 1992). It is believed that the phenolic hydroxyl group of the fraxin acts as a reducing agent and form an intermediate complex with the $\mathrm{Ag}^{+}$ion and finally reduces it to $\mathrm{Ag}^{0}$, thereby they themselves get oxidized to corresponding carbonyl groups Pathway 1 , and consequently it becomes logical to reason that the AgNPs prepared in this study should be stabilized by phenolic 


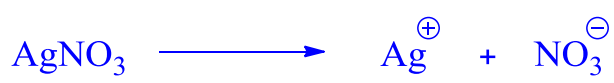

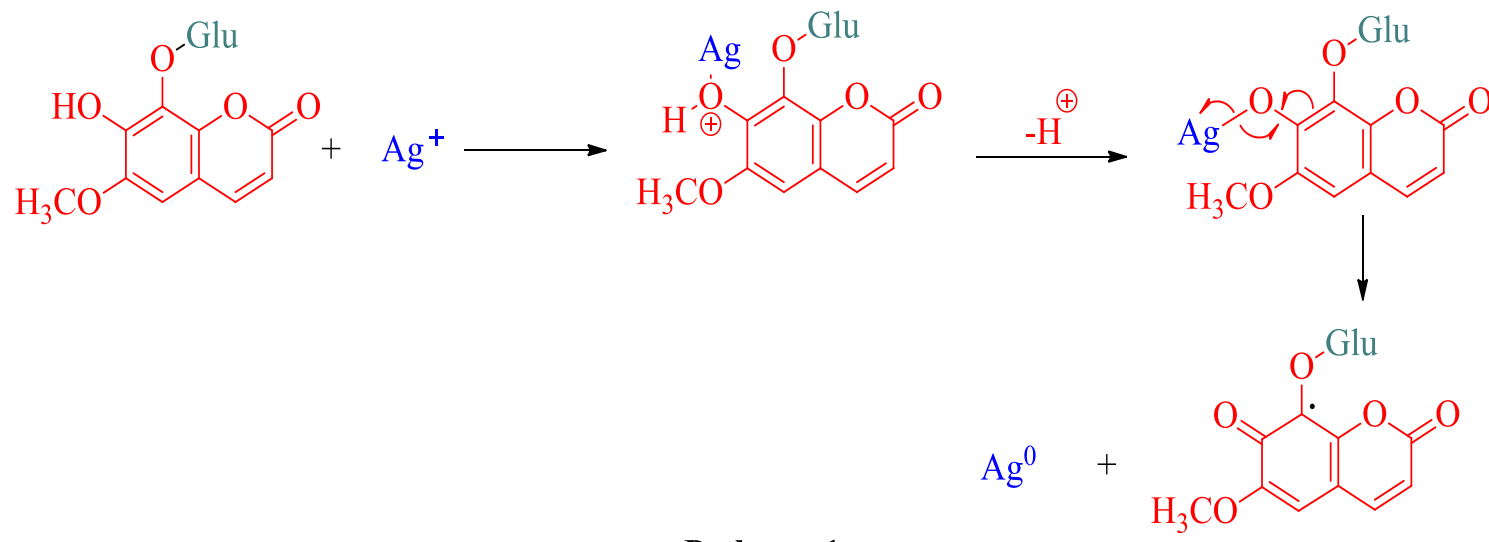

Pathway 1

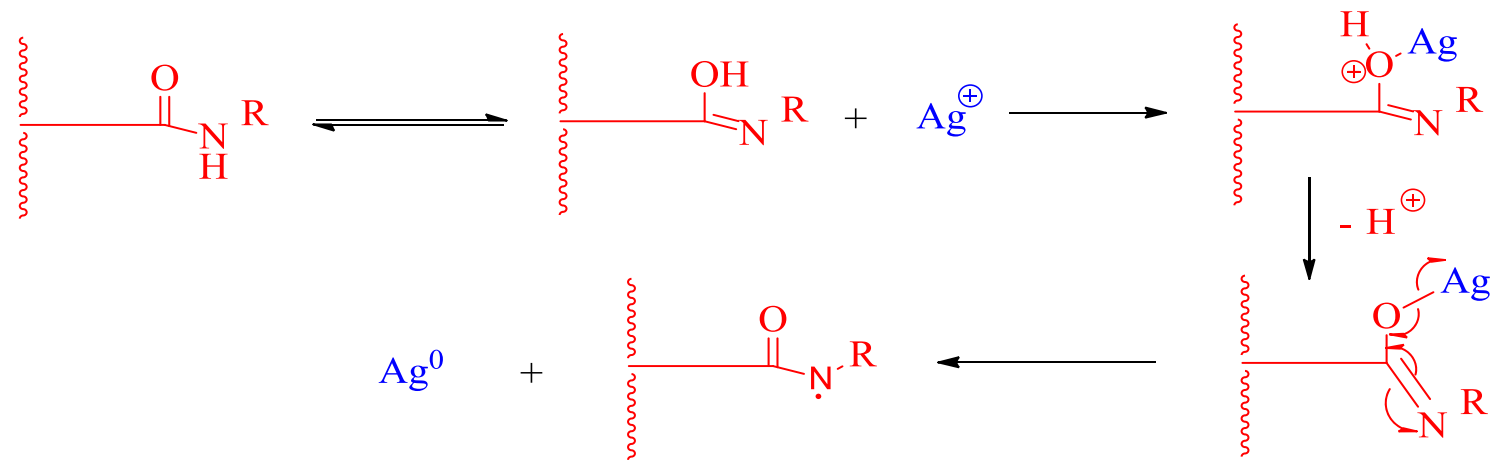

Pathway 2

Scheme 1 Possible mechanistic pathway for the reduction of $\mathrm{Ag}^{+}$ion by the plant extract

molecules through the carbonyl groups. Similarly, a little change in the IR frequencies of the crude aqueous extract and silver nanoparticles in the amide functional group region (Fig. 3) suggest its side role in the reduction process of $\mathrm{Ag}^{+}$ion as shown in Pathway 2.

\section{SEM and EDX analysis}

The morphology and size of the synthesized nanoparticles have been characterized on the basis of SEM technique. SEM analysis showed uniformly distributed silver nanoparticles on the surfaces of the cells Fig. 4. The silver nanoparticles are almost spherical in shape with smooth morphology and particle size ranging from 25 to $40 \mathrm{~nm}$. The presence of the larger sized silver nanoparticles observed during SEM analysis may be attributed to the aggregation of the smaller silver nanoparticles during SEM measurements. Energy dispersive X-ray spectroscopy (Fig. 5) elucidates the chemical nature of the synthesized silver nanoparticles using Fraxinus excelsior leaf extract. The EDX profile displayed a strong peak at the energy of $3 \mathrm{keV}$ for silver and also some of the weak peaks for $\mathrm{C}, \mathrm{O}, \mathrm{Cl}$ were observed which may have originated from the biomolecules bound to the surface of the silver nanoparticles. The emission energy at $3 \mathrm{keV}$ indicates the reduction of 

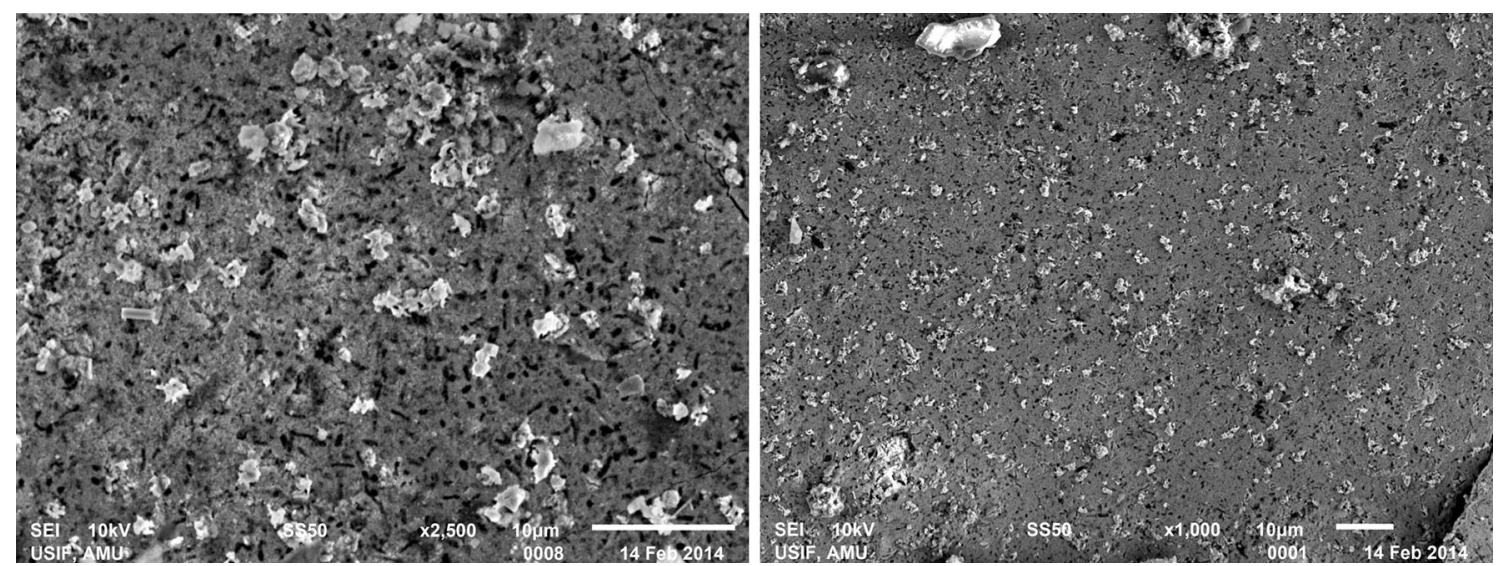

Fig. 4 SEM micrograph of AgNPs synthesized from $2 \mathrm{~mL}$ leaf extract treated with $5 \times 10^{-3} \mathrm{M} \mathrm{AgNO}_{3}$ solution
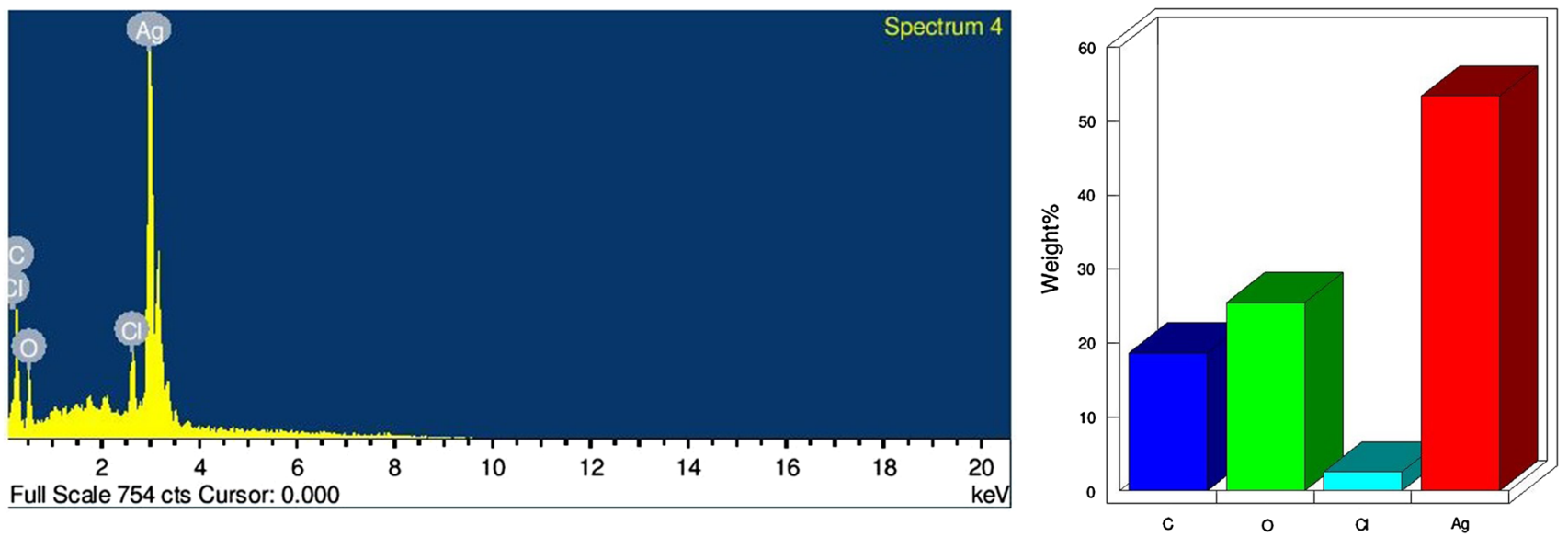

Fig. 5 EDX Spectrum of synthesized AgNPs with $2 \mathrm{~mL}$ leaf extracts solution and $5 \times 10^{-3} \mathrm{M} \mathrm{AgNO}_{3}$ solution

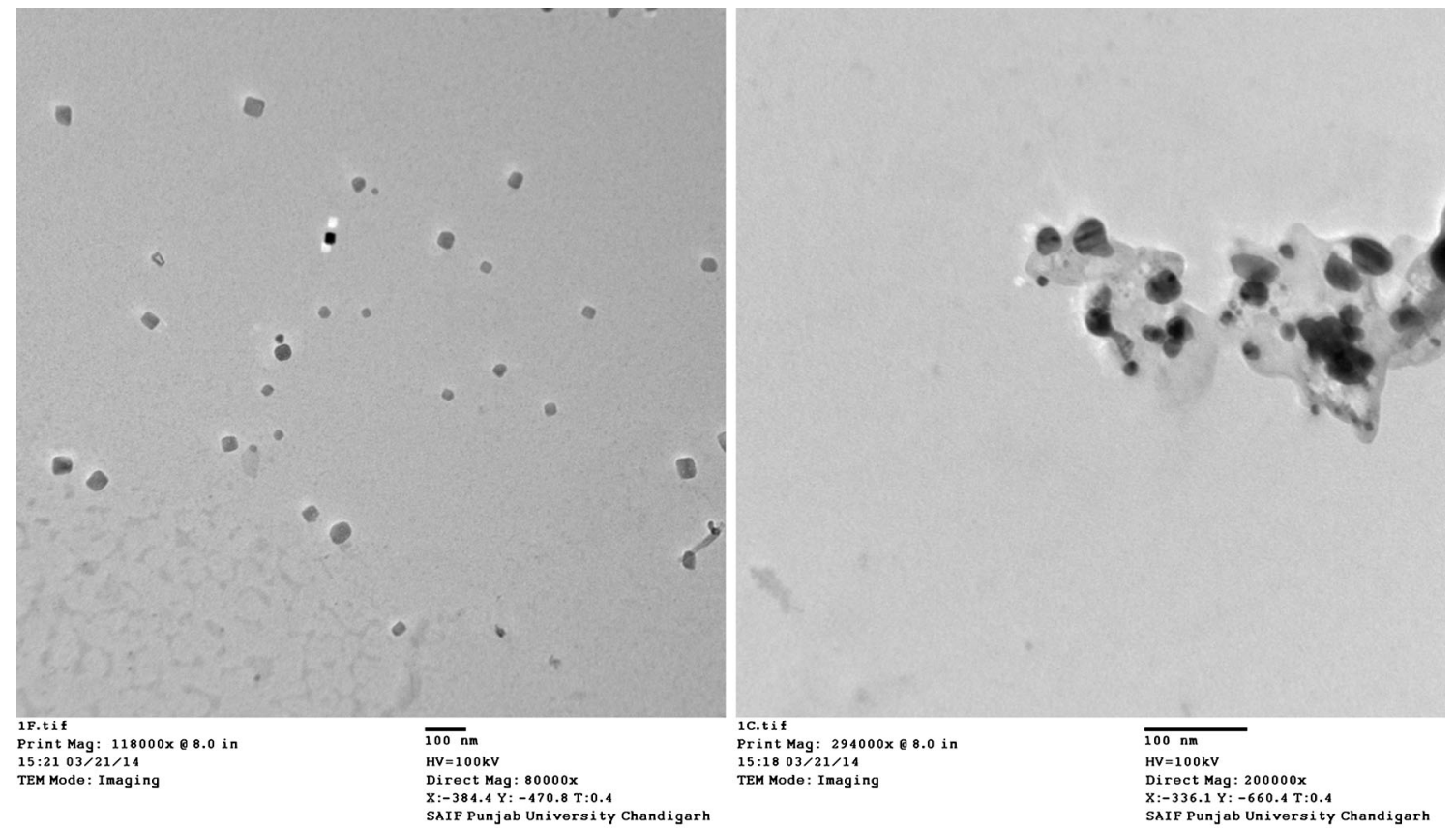

Fig. 6 TEM image of AgNPs synthesized from $2 \mathrm{~mL}$ leaf extract treated with $5 \times 10^{-3} \mathrm{M} \mathrm{AgNO}_{3}$ solution 
silver ions to the elemental silver $\left(\mathrm{Ag}^{0}\right)$ (Vanaja et al. 2013).

\section{TEM analysis}

Transmission electron microscopy was used to provide further insight into the size, shape and morphology of the synthesized silver nanoparticles. The TEM images were recorded from drop-coated films of the silver nanoparticles synthesized by treating silver nitrate solution with aqueous leaf extract of Fraxinus excelsior Fig. 6. The TEM images reveals that the synthesized silver nanoparticles formed were predominantly spherical and polydisperse with diameters in the range $25-40 \mathrm{~nm}$. It is obvious from the TEM image Fig. 5 that the silver nanoparticles are surrounded by

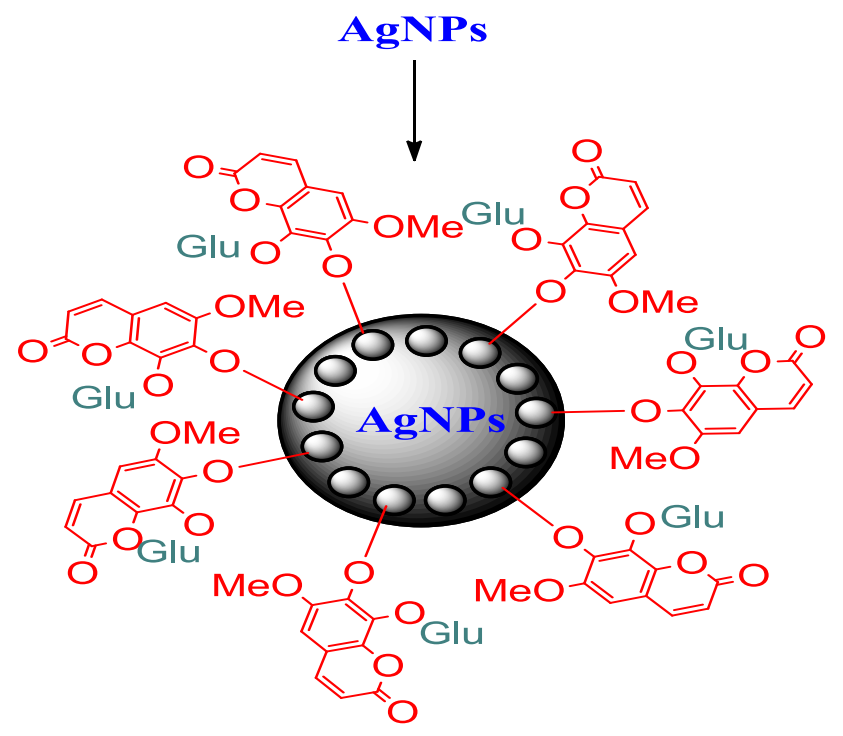

Fig. 7 Stabilization of synthesized AgNPs a faint thin layer of other material, which is believed to be the capping organic material from the aqueous leaf extract. These capping organic materials prevent the aggregation of the silver nanoparticles and thus provide extra stability to the synthesized silver nanoparticles Fig. 7. This capping of silver nanoparticles by organic materials further enhances their life time in solution up to four weeks after synthesis (Shankar et al. 2004; Song and Kim 2009), thus making the utilization of plant extracts as a promising candidate for the synthesis of bio-conjugated silver nanoparticles.

\section{DPPH scavenging assay}

The antioxidant activity of the aqueous extract, ethanolic extract and bio-conjugated AgNPs was evaluated using DPPH scavenging assay. The $\mathrm{IC}_{50}$ values of both extracts and synthesized AgNPs are reported in Table 1. It can be inferred from the data that synthesized AgNPs displayed better antioxidant activity in comparison to both the extracts. As can be seen from Table 1, there was a dose dependent increase in the percentage inhibition (\% inhibition) of extracts and synthesized silver nanoparticles. The recorded value (\% inhibition) for the lowest concentration ( $2 \mu \mathrm{g} / \mathrm{mL})$ of the aqueous and ethanol extract was 9.83 and 12.44 respectively and this value was increased to 66.55 and 67.92 respectively when the concentration was increased to $10 \mu \mathrm{g} / \mathrm{mL}$. However, for AgNPs the percent inhibition values recorded were 18.32 and 86.18 for the concentration of 2 and $10 \mu \mathrm{g} / \mathrm{mL}$ respectively, these values indicate that the synthesized bio-conjugated AgNPs have better antiradical potential than the extracts alone. The DPPH free radical scavenging assay of the synthesized silver nanoparticle (AgNPs) when compared with the standard ascorbic acid showed promising activity. It was

Table 1 Quantitative screening of antioxidant activity of plant extracts and AgNPs by DPPH assay

\begin{tabular}{|c|c|c|c|c|c|c|c|c|}
\hline \multirow[t]{2}{*}{ S. No } & \multirow[t]{2}{*}{ Compound } & \multirow[t]{2}{*}{ Absorbance } & \multicolumn{6}{|c|}{ Absorbance at $517 \mathrm{~nm}$} \\
\hline & & & $2 \mu \mathrm{g} / \mathrm{mL}$ & $4 \mu \mathrm{g} / \mathrm{mL}$ & $6 \mu \mathrm{g} / \mathrm{mL}$ & $8 \mu \mathrm{g} / \mathrm{mL}$ & $10 \mu \mathrm{g} / \mathrm{mL}$ & $\mathrm{IC}_{50}(\mu \mathrm{G} / \mathrm{ML})^{\mathrm{a}}$ \\
\hline 1 & Control & $\left(\mathrm{Abs}_{\mathrm{Control}}\right)$ & $0.9425 \pm 0.04$ & $0.9425 \pm 0.02$ & $0.9425 \pm 0.01$ & $0.9425 \pm 0.05$ & $0.9425 \pm 0.04$ & \\
\hline 2 & Ethanol extract & $\begin{array}{l}\left(\mathrm{Abs}_{\text {Sample }}\right) \\
\% \mathrm{SA}\end{array}$ & $\begin{array}{l}0.8252 \pm 0.01 \\
12.44\end{array}$ & $\begin{array}{l}0.7225 \pm 0.03 \\
23.34\end{array}$ & $\begin{array}{l}0.5523 \pm 0.05 \\
41.40\end{array}$ & $\begin{array}{l}0.4002 \pm 0.07 \\
57.53\end{array}$ & $\begin{array}{l}0.3023 \pm 0.02 \\
67.92\end{array}$ & 7.01 \\
\hline 3 & Aqueous extract & $\begin{array}{l}\left(\mathrm{Abs}_{\text {sample }}\right) \\
\% \mathrm{SA}\end{array}$ & $\begin{array}{l}0.8498 \pm 0.03 \\
9.83\end{array}$ & $\begin{array}{l}0.7520 \pm 0.04 \\
20.21\end{array}$ & $\begin{array}{l}0.6530 \pm 0.01 \\
30.71\end{array}$ & $\begin{array}{l}0.4830 \pm 0.06 \\
48.75\end{array}$ & $\begin{array}{l}0.3152 \pm 0.04 \\
66.55\end{array}$ & 8.40 \\
\hline 4 & Plant-AgNPs & $\begin{array}{l}\left(\mathrm{Abs}_{\mathrm{sample}}\right) \\
\% \mathrm{SA}\end{array}$ & $\begin{array}{l}0.7694 \pm 0.01 \\
18.32\end{array}$ & $\begin{array}{l}0.6168 \pm 0.03 \\
34.52\end{array}$ & $\begin{array}{l}0.4336 \pm 0.04 \\
53.99\end{array}$ & $\begin{array}{l}0.2870 \pm 0.05 \\
69.54\end{array}$ & $\begin{array}{l}0.1302 \pm 0.04 \\
86.18\end{array}$ & 5.71 \\
\hline 5 & Standard (ascorbic acid) & $\begin{array}{l}\left(\mathrm{Abs}_{\text {sample }}\right) \\
\% \mathrm{SA}\end{array}$ & $\begin{array}{l}0.7850 \pm 0.04 \\
16.71\end{array}$ & $\begin{array}{l}0.5230 \pm 0.05 \\
44.50\end{array}$ & $\begin{array}{l}0.4023 \pm 0.04 \\
57.31\end{array}$ & $\begin{array}{l}0.3180 \pm 0.01 \\
66.25\end{array}$ & $\begin{array}{l}0.1625 \pm 0.02 \\
82.75\end{array}$ & 4.80 \\
\hline
\end{tabular}

$S E M$ standard error of the mean

${ }^{\text {a }} \mathrm{IC}_{50}$ value represents the concentration (mean $\pm \mathrm{SEM}$ of three experiments) required to exhibit $50 \%$ antioxidant activity 


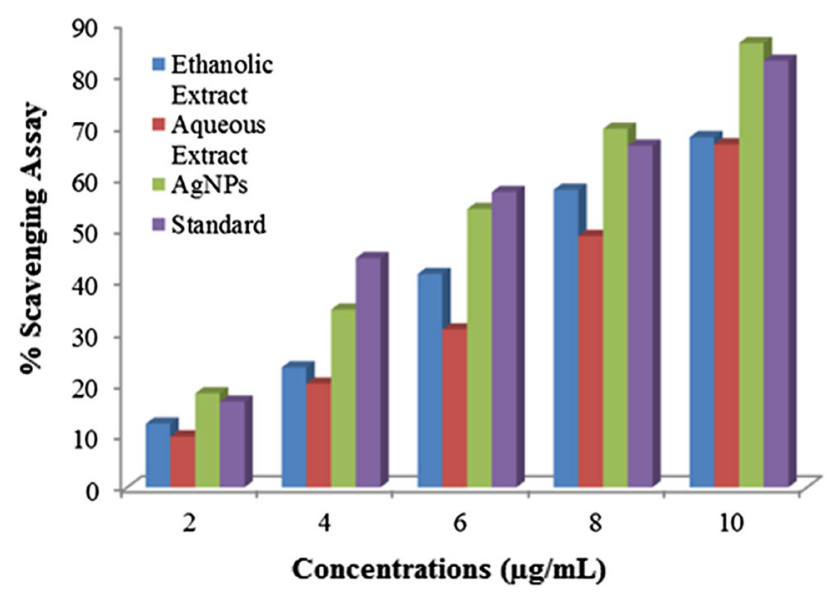

Fig. 8 Antiradical activity of plant extracts (aqueous and ethanol) and synthesized AgNPs in comparison to reference drug ascorbic acid

found that at a concentration of 8 and $10 \mu \mathrm{g} / \mathrm{mL}$, the bioconjugated AgNPs exhibited better free radical scavenging activity than the reference drug ascorbic acid Fig. 8. These results suggest that at concentrations of above $10 \mu \mathrm{g} / \mathrm{mL}$, the synthesized AgNPs may serve as potent radical scavengers. The $\mathrm{IC}_{50}$ values of the extracts and the AgNPs were found in the order: AgNPs $>$ ethanol extracts $>$ aqueous extracts. The AgNPs exhibited promising $\mathrm{IC}_{50}$ value $(5.71 \mu \mathrm{g} / \mathrm{mL})$ almost close to the reference drug $\left(\mathrm{IC}_{50}\right.$ value $4.80 \mu \mathrm{g} / \mathrm{mL}$ ). All these results suggest that intercalation of bio extracts with silver nanoparticles can serve as promising antiradical agents.

\section{Conclusion}

The present work reports the facile, convenient and ecofriendly, Fraxinus excelsior extract mediated green synthesis of bio-conjugated silver nanoparticles using microwave. The characterization with UV-Vis spectroscopy, FT-IR, SEM, TEM and EDX analysis authenticate the formation of target silver nanoparticles. TEM analysis depicts the stabilization of synthesized nanoparticles by the capping organic materials thereby preventing their agglomeration. The synthesized silver nanoparticles exhibited promising ability to diffuse the toxic free radicals and can be used as a possible food additive or in nutraceutical and biopharmaceutical industries.

Acknowledgments Authors thank the Chairman, Department of Chemistry, A.M.U, Aligarh, for providing necessary research facilities, University Sophisticated Instrument Facility (USIF), AMU, Aligarh for providing SEM-EDX and spectral analysis, SAIF Panjab University Chandigarh for TEM analysis. UGC is also gratefully acknowledged for research fellowship to Faheem Ahmad, Ali Mohammed Malla and Shaista Azaz.
Open Access This article is distributed under the terms of the Creative Commons Attribution License which permits any use, distribution, and reproduction in any medium, provided the original author(s) and the source are credited.

\section{References}

Ahmed A, Mukherjee P, Senapati S, Mandal D, Khan MI, Kumar R, Satyr M (2003) Extracellular biosynthesis of silver nanoparticles using the fungus Fusarium oxysporum. Colloids Surf B 28:313-318

Arunachalam KD, Annamalai SK, Hari S (2013) One-step green synthesis and characterization of leaf extract-mediated biocompatible silver and gold nanoparticles from Memecylon umbellatum. Int J Nanomed 8:1307-1315

Begum NA, Mondal S, Basu S, Laskar RA, Mandal D (2009) Biogenic synthesis of $\mathrm{Au}$ and $\mathrm{Ag}$ nanoparticles using aqueous solutions of black tea leaf extracts. Colloids Surf B 71:113-118

Boca SC, Potara M, Gabudean AM, Juhem A, Baldeck PL, Astilean S (2011) Chitosan-coated triangular silver nanoparticles as a novel class of biocompatible, highly effective photothermal transducers for in vitro cancer cell therapy. Cancer Lett 31:131-140

Burda C, Chen X, Narayanan R, El-Sayed MA (2005) Chemistry and properties of nanocrystals of different shapes. Chem Rev 105:1025-1102

Chaloupka K, Malam Y, Seifalian AM (2010) Nanosilver as a new generation of nanoproduct in biomedical applications. Trends Biotechnol 28:580-588

Chaudhry Q, Castle L (2011) Food applications of nanotechnologies: an overview of opportunities and challenges for developing countries. Trends Food Sci Technol 22:595-603

Damtoft S, Franzyk H, Jensen WR (1992) Excelsioside, a secoiridoid glucoside from Fraxinus excelsior. Phytochemistry 31:4197-4201

Dankovich TA, Gray DG (2011) Bactericidal paper impregnated with silver nanoparticles for point-of-use water treatment. Environ Sci Technol 45:1992-1998

Doria G, Conde J, Veigas B, Giestas L, Almeida C, Assuncao M, Rosa J, Baptista PV (2012) Noble metal nanoparticles for biosensing applications. Sensors 12:1657-1687

Eddouks M, Maghrani M, Lemhadri A, Ouahidi ML, Jouad H (2002) Ethnopharmacological survey of medicinal plants used for the treatment of diabetes mellitus, hypertension and cardiac diseases in the south-east region of Morocco. J Ethnopharmacol 82:97-103

Ghazaly ME, Khayyal MT, Okpanyi SN, Corell MA (1992) Study of the anti-inflammatory activity of Populus tremula, Solidago virgaurea and Fraxinus excelsior. Drug Res 42:333-336

Hemmer W, Focke M, Wantke F, Gotz M, Jarisch R, Jager S (2000) Ash (Fraxinus excelsior) pollen allergy in central Europe: specific role of pollen pan allergens and the major allergen of ash pollen. Allergy 55:923-930

Jain J, Arora S, Rajwade JM, Omray P, Khandelwal S, Paknikar KM (2009) Silver nanoparticles in therapeutics: development of an antimicrobial gel formulation for topical use. Mol Pharm 6:1388-1401

Jiang H, Moon KS, Zhang Z, Pothukuchi S, Wong CP (2006) Variable frequency microwave synthesis of silver nanoparticles. J Nanopart Res 8:117-124

Juan ZY, Rao H, Fang ZX, Zhou WL, Xu WC (2012) Synthesis, properties and optical applications of noble metal nanoparticlebiomolecule conjugates. Chin Sci Bull 57:238-246

Kato K, Terao S, Shimamoto N, Hirata M (1988) Studies on scavengers of active oxygen species I. Synthesis and biological activity of 2-O-alkylascorbic acids. J Med Chem 31:793-798 
Kelly FM, Johnston JH (2011) Colored and functional silver nanoparticle-wool fiber composites. ACS Appl Mater Interf 3:1083-1092

Knoll B, Keilmann F (1999) Near-field probing of vibrational absorption for chemical microscopy. Nature 399:134-137

Krishnaraj C, Jagan EG, Rajasekar S, Selvakumar P, Kalaichelvan PT, Mohan N (2010) Synthesis of silver nanoparticles using Acalypha indica leaf extracts and its antibacterial activity against water borne pathogens. Colloids Surf B 76:50-56

Kumar P, Singh P, Kumari K, Mozumdar S, Chandra RA (2011) Green approach for the synthesis of gold nano triangles using aqueous leaf extract of Callistemon viminalis. Mater Lett 65:595-597

Lanone S, Boczkowski J (2006) Biomedical applications and potential health risks of nanomaterials: molecular mechanisms. Curr Mol Med 6:651-663

Lin Z, Wu J, Xue R, Yong Y (2005) Spectroscopic characterization of $\mathrm{Au}^{3+}$ biosorption by waste biomass of Saccharomyces cerevisiae. Spectrochim Acta A 61:761-765

Middleton P, Stewart F, Qahtani SA, Egan P, Rourke CO, Abdulrahman A, Byres M, Middleton M, Kumarasamy Y, Shoeb M, Nahar L, Delazar A, Sarker SD (2005) Antioxidant, antibacterial activities and general toxicity of Alnus glutinosa, Fraxinus excelsior and Papaver rhoeas. Iranian J Pharm Res 2:81-86

Monto F, Arce C, Noguera MA, Ivorra MD, Flanagan J, Roller M, Issaly N, Docon P (2014) Action of an extract from the seeds of Fraxinus excelsior L. on metabolic disorders in hypertensive and obese animal models. Food Funct 5:786-796

Mulvaney P (1996) Surface plasmon spectroscopy of nanosized metal particles. Langmuir 12:788-800

Murphy CJ (2008) Sustainability as an emerging design criterion in nanoparticle synthesis and applications. J Mater Chem 18:2173-2176

Nadagouda MN, Speth T, Varma RS (2011) Microwave-assisted green synthesis of silver nanostructures. Acc Chem Res 44:469-478

Nair R, Varghese SH, Nair BG, Maekawa T, Yoshida Y, Kumar DS (2010) Nanoparticulate material delivery to plants. Plant Sci 179:154-163

Navaladian S, Viswanathan B, Viswanath RP, Varadarajan TK (2007) Thermal decomposition as route for silver nanoparticles. Nanoscale Res Lett 2:44-48

Niraimathi KL, Sudha V, Lavanya R, Brindha P (2013) Biosynthesis of silver nanoparticles using Alternanthera sessilis (Linn.) extract and their antimicrobial, antioxidant activities. Colloids Surf B 102:288-291

Otari SV, Patil RM, Nadaf NH, Ghosh SJ, Pawar SH (2012) Green biosynthesis of silver nanoparticles from an actinobacteria Rhodococcus sp. Mater Lett 72:92-94

Pauksch L, Hartmann S, Rohnke M, Szalay G, Alt V, Schnettler R, Lips KS (2014) Biocompatibility of silver nanoparticles and silver ions in primary human mesenchymal stem cells and osteoblasts. Acta Biomater 10:439-449
Prabhu S, Poulose EK (2012) Silver nanoparticles: mechanism of antimicrobial action, synthesis, medical applications, and toxicity effects. Int Nano Lett 2:1-10

Prow TW, Grice JE, Lin LL, Faye R, Butler M, Becker W, Wurm EMT, Yoong C, Robertson TA, Soyer HP, Roberts MS (2011) Nanoparticles and microparticles for skin drug delivery. Adv Drug Deliv Rev 63:470-491

Ramya M, Subapriya MS (2012) Green synthesis of silver nanoparticles. Int J Pharm Med Biol Sci 1:54-61

Renwart PP, Tits M, Wauters JN, Angenot L (1992) Reversed-phase HPTLC densitometric evaluation of fraxin in Fraxinus excelsior leaves. J Pharm Biomed Anal 10:1089-1091

Roopan SM, Rohit Madhumitha G, Rahuman AA, Kamaraj C, Bharathi A, Surendra TV (2013) Low-cost and eco-friendly phyto-synthesis of silver nanoparticles using Cocos nucifera coir extract and its larvicidal activity. Ind Crop Prod 43:631-635

Sankar R, Karthik A, Prabu A, Karthik S, Shivashangari KS, Ravikumar V (2013) Origanum vulgare mediated biosynthesis of silver nanoparticles for its antibacterial and anticancer activity. Colloids Surf B 108:80-84

Shankar SS, Rai A, Ahmad A, Sastry M (2004) Rapid synthesis of Au, Ag and bimetallic $\mathrm{Au}$ core-Ag shell nanoparticles using Neem (Azadirachta indica) leaf broth. J Colloid Interface Sci 275:496-502

Silver S (2003) Bacterial silver resistance: molecular biology and uses and misuses of silver compounds. FEMS Microbiol Rev 27:341-353

Song JY, Kim BS (2009) Rapid biological synthesis of silver nanoparticles using plant leaf extracts. Bioproc Biosyst Eng 32:79-84

Sreeram KS, Nidin M, Nair BU (2008) Microwave assisted template synthesis of silver nanoparticles. Bull Mater Sci 31:937-942

Starowicz M, Stypula B, Banas J (2006) Electrochemical synthesis of silver nanoparticles. Electrochem Commun 8:227-230

Tessier PM, Velev OD, Kalambur AT, Rabolt JF, Lenhoff AM, Kaler EW (2000) Assembly of gold nanostructured films templated by colloidal crystals and use in surface-enhanced raman spectroscopy. J Am Chem Soc 122:9554-9555

Tsuji M, Hashimoto M, Nishizawa Y, Kubokawa M, Tsuji T (2005) Microwave-assisted synthesis of metallic nanostructures in solution. Chemistry 11:440-452

Vanaja M, Gnanajobitha G, Kumar KP, Kumar SR, Malarkodi C, Annadura G (2013) Phytosynthesis of silver nanoparticles by Cissus quadrangularis: influence of physicochemical factors. J Nanostruct Chem 3:1-8

Visen P, Saraswat B, Visen A, Roller M, Bily A, Mermet C, He K, Bai N, Lemaire B, Lafay S, Ibarr A (2009) Acute effects of Fraxinus excelsior L. seed extract on postprandial glycemia and insulin secretion on healthy volunteers. J Ethnopharmacol 126:226-232

Wang EC, Wang AZ (2014) Nanoparticles and their applications in cell and molecular biology. Integr Biol 6:9-26 